\title{
Host Susceptibility Hypothesis for Shell Disease in American Lobsters
}

\author{
Michael F. TLusty* \\ New England Aquarium, Boston, Massachusetts 02110, USA \\ Roxanna M. SMOLOWITZ ${ }^{1}$ \\ Marine Biological Laboratory, 7 MBL Street, Woods Hole, Massachusetts 02543, USA \\ Harlyn O. Halvorson \\ University of Massachusetts, Boston, Massachusetts 02125, USA \\ Simone E. DeVito \\ New England Aquarium, Boston, Massachusetts 02110, USA
}

\begin{abstract}
Epizootic shell disease (ESD) in American lobsters Homarus americanus is the bacterial degradation of the carapace resulting in extensive irregular, deep erosions. The disease is having a major impact on the health and mortality of some American lobster populations, and its effects are being transferred to the economics of the fishery. While the onset and progression of ESD in American lobsters is undoubtedly multifactorial, there is little understanding of the direct causality of this disease. The host susceptibility hypothesis developed here states that although numerous environmental and pathological factors may vary around a lobster, it is eventually the lobster's internal state that is permissive to or shields it from the final onset of the diseased state. To support the host susceptibility hypothesis, we conceptualized a model of shell disease onset and severity to allow further research on shell disease to progress from a structured model. The model states that shell disease onset will occur when the net cuticle degradation (bacterial degradation, decrease of host immune response to bacteria, natural wear, and resorption) is greater than the net deposition (growth, maintenance, and inflammatory response) of the shell. Furthermore, lesion severity depends on the extent to which cuticle degradation exceeds deposition. This model is consistent with natural observations of shell disease in American lobster.
\end{abstract}

The American lobster Homarus americanus is iconic to northeastern North America. It ranges from Newfoundland-Labrador to North Carolina and is harvested by small-boat fishermen from small coastal communities throughout the species' range. American lobsters support the most valuable fishery in this region. In 2003, U.S. landings of American lobster were valued at US\$285.6 × $10^{6}$ (National Marine Fisheries Service [NMFS], Fisheries Statistics Division, personal communication). The total economic impact of this fishery is estimated at $\$ 2.4-\$ 4.0 \times 10^{9}$ annually (R. Bayer, Lobster Institute, personal communication).

The inshore fishery for American lobster is recruitment based and therefore is vulnerable to disruptions in larval supply and survival of prerecruit lobsters (Wahle

\footnotetext{
* Corresponding author: mtlusty@neaq.org

${ }^{1}$ Present address: New England Aquarium, Boston, Massachusetts 02110, USA.
}

Received March 6, 2006; accepted June 17, 2007

Published online December 31, 2007 et al. 2004). However, even with continued record landings, geographically identifiable populations have experienced severe declines indicative of disease or environmental problems primarily noticeable in adult lobsters. The most notable declines have occurred toward the southern extent of the American lobster's range. In 1998, the Long Island Sound (LIS) fishery caught $9.5 \times 10^{6} \mathrm{lb}$ of lobsters with a dockside value of approximately $\$ 33 \times 10^{6}$. The population crash of 1999 eliminated fishing in many parts of the sound, impacting 1,300 fishermen as landings decreased by 92\% (Balcom and Howell 2006). Similarly, the Rhode Island fishery experienced a $50 \%$ decline in landings value (from $\$ 32 \times 10^{6}$ to $\$ 16 \times 10^{6}$ ) between 1999 and 2003 (NMFS, Fisheries Statistics Division, personal communication). While various factors are implicated in these population declines, disease issues are pervasive and indicate that long-term health of the American lobster stock may be compromised.

One of the more noticeable diseases affecting lobsters in the southern extent of their range is epizootic shell disease (ESD; Figure 1). Epizootic shell 


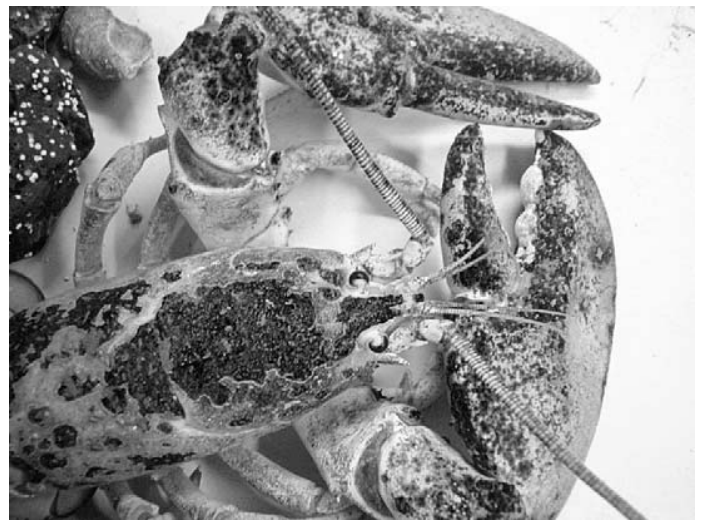

FIGURE 1.-Photograph (by M.F.T.) of an American lobster with shell disease.

disease results from bacterial erosion of the carapace. The reasons for this increase in the ability of bacteria to penetrate the carapace are unknown. This form of shell disease is reportedly progressing northward and appears to be increasing in prevalence into the more productive waters off northern Massachusetts and New Hampshire, potentially spreading into the waters surrounding Maine. These three states accounted for $88 \%$ of U.S. lobster landings in 2003. Thus, it is imperative to understand why ESD is spreading up the coast. Here, we describe ESD in American lobsters, discuss proximate causative factors, describe a simplification of a conceptual shell disease model recently advanced by Castro et al. (2006), and conclude by addressing what courses of action are necessary to further understand ESD.

\section{Description of Epizootic Shell Disease}

Epizootic shell disease is one of three degenerative cuticular diseases exhibited by lobsters (Sindermann 1979; Smolowitz et al. 1992, 2005a, 2005b; Table 1). Shell diseases that have been described for other species of Crustacea appear to be more similar in pathology and etiology to impoundment shell disease (ISD) rather than to ESD (Bullis 1988; Noga et al. 1994; Goarant et al. 2000; Porter et al. 2001; Vogan et al. 2002).

Epizootic shell disease is characterized by invasion (superficial to deep) of the lobster's carapace in which irregular, deep erosions (true ulceration is rare) appear primarily on the dorsum of the cephalothorax and rostrum and fewer erosions appear on the abdominal segments (Smolowitz et al. 2005a, 2005b). The arthrodial membranes (joints) are also rarely affected. The inflammatory, hemocytic response is appropriate within moderately severe erosions. Reports of full ESD onset range from 1 week (Castro et al. 2005) to several months (Sullivan and Nelson 2005). Molting may limit the spread of the disease within individuals, as $37 \%$ of diseased American lobsters did not have the disease upon recapture (Landers 2005).

Histologically, at the leading edges of the lesions, ESD erosions exhibit vertical channels that are often regularly spaced and similar to the distribution of pore canals (Smolowitz et al. 2005a). The pores provide a portal that can give direct access into the carapace. The erosions trigger the melanization response (activation of hydroxyphenols and phenolases; Neville 1975) in the upper cuticle. In the lower, uncalcified endocuticle, the melanization response relies on hemocytic proteins transported to the inflamed location. There is no

TABLE 1.-Description of three major types of shell disease in American lobsters.

\begin{tabular}{|c|c|c|c|c|}
\hline Type & Appearance & Environmental correlates & Prevalent organisms & Source \\
\hline Burn spot & $\begin{array}{l}\text { Individual, circular, } \\
\text { blackened lesions at } \\
\text { various locations on the } \\
\text { body }\end{array}$ & Pollution & $\begin{array}{l}\text { Fungal invasions, } \\
\text { bacteria, or both }\end{array}$ & $\begin{array}{l}\text { Rosen (1970); Burns et } \\
\text { al. (1979); Sindermann } \\
\text { (1979); Stewart (1980) }\end{array}$ \\
\hline $\begin{array}{l}\text { Impoundment shell } \\
\text { disease }\end{array}$ & $\begin{array}{l}\text { Round, blackened, focal } \\
\text { erosions (bilaterally } \\
\text { symmetrical; centered } \\
\text { around setal cores), } \\
\text { primarily on the } \\
\text { carapace dorsum, } \\
\text { which overlap as } \\
\text { disease worsens }\end{array}$ & $\begin{array}{l}\text { Overcrowding, poor water } \\
\text { quality, and inadequate } \\
\text { diets associated with } \\
\text { winter impoundment }\end{array}$ & Bacteria (Vibrio spp.) & Smolowitz et al. (1992) \\
\hline Epizootic shell disease & $\begin{array}{l}\text { Irregular dorsal midline } \\
\text { erosions into the } \\
\text { carapace of the } \\
\text { cephalothorax; erosions } \\
\text { are characterized by a } \\
\text { brown/tan/black, } \\
\text { irregular, granular } \\
\text { surface }\end{array}$ & $\begin{array}{l}\text { Increased environmental } \\
\text { temperature; lessened } \\
\text { ability of the lobster to } \\
\text { remove such bacteria } \\
\text { effectively }\end{array}$ & $\begin{array}{l}\text { Gram-negative bacteria, } \\
\text { mostly appearing as } \\
\text { stacks of short rods } \\
\text { (Flavobacteriaceae and } \\
\text { perhaps } \alpha \text { - } \\
\text { proteobacteria) }\end{array}$ & $\begin{array}{l}\text { Chistoserdov, et al. } \\
\text { (2005a, 2005b); } \\
\text { Smolowitz et al. } \\
(2005 \mathrm{a}, 2005 \mathrm{~b})\end{array}$ \\
\hline
\end{tabular}


evidence to suggest that the bacteria responsible for ESD originate internally with subsequent infection of the shell, as there is no correlation between bacteria in the hemolymph and those on the shell (Chistoserdov et al. 2005a). The bacteria that colonize the shell do not enter the soft tissue of the affected animals. Unaffected, healthy lobsters have significantly fewer bacteria on the surface of their carapaces than do shell-diseased lobsters (Hsu and Smolowitz 2003). Scanning electron microscope studies of affected lobsters show that an undiseased carapace from an affected animal has very low to rarely moderate numbers of bacteria on the surface (around setae), while an ESD carapace is covered with layers of bacteria (Hsu and Smolowitz 2003).

All forms of shell disease are caused by chitinolytic microorganisms that are ubiquitous in the marine environment (Fisher et al. 1978; Malloy 1978; Smolowitz et al. 1992). These organisms utilize chitin, the principal component of the crustacean cuticle, as a source of energy, carbon, and nitrogen (Rosen 1970). Organic acids are produced as an end product in chitin digestion (Okutani and Kitada 1968), which dissolve and chelate calcium embedded in the shell to further erode its structure (Rosen 1970). For these organisms to attack the chitinous layer of the cuticle, chitinoclastic microorganisms must be able to breach the waxy, chitinless epicuticle (Rosen 1970; Fisher et al. 1978). Lipolytic bacteria present in the biofilm might have a role in breaking down the epicuticle, subsequently allowing the chitinoclastic microorganisms into the exo- and endocuticles (Rosen 1970; Fisher et al. 1978; Sindermann 1979; Smolowitz et al. 1992).

The types of bacteria isolated from wild, healthy lobsters and those with ESD were similar in diversity (although not quantity), suggesting that the disease is an opportunistic infection caused by microbiota that can be found on unaffected animals (Chistoserdov et al. 2005b; Sullivan and Nelson 2005). Chistoserdov et al. (2005a) demonstrated that microbial communities of ESD lesions on American lobsters from different geographical areas (Maine; Buzzards Bay, Massachusetts; and LIS, New York) were similar in composition. However, members of the family Flavobacteriaceae were the only bacteria identified in the lesions of every affected animal. This is the first convincing line of evidence that this group of bacteria is important in the occurrence of ESD. Interestingly, this finding is consistent with disease findings in other species of animals, since members of Flavobacteriaceae, which are ubiquitous in the environment, also cause severe ulcerative dermatitis in a variety of aquatic organisms (Kluge 1965; Wakabayashi et al. 1980; Green et al. 1999).
Other bacteria were observed in ESD lesions; these included an unknown $\alpha$-proteobacterium in Maine samples, and Pseudoalteromonas spp., which were present in samples from LIS (particularly central areas) and Buzzards Bay (Chistoserdov et al. 2005a). Restriction fragment length polymorphism and $16 \mathrm{~S}$ ribosomal DNA sequencing analyses confirmed that all Pseudoalteromonas spp. isolates were $P$. gracilis. While the samples from ESD lesions contained chitinolytic bacteria, these were a minor component of the total count of viable bacteria (Chistoserdov et al. 2005a).

The bacteria reside in the biofilm that covers the cuticle (reviewed in Hall-Stoodley et al. 2004). A biofilm is a complex structure that includes microcolonies in a heterogeneous matrix (Lawrence et al. 1991) along with channels to assist nutrient uptake and waste exchange (Stoodley et al. 1994). Biofilms contain multiple bacteria (Ivanov et al. 2006) and subpopulations of more-pathogenic or resistant bacteria (Suci and Tyler 2003). Biofilms may also be host to facultative or competitive interactions, including predator-prey dynamics within micro- and amoebic communities that affect the composition of the bacterial community on the surface of the carapace (O'Kelly 2005). This, when combined with the heterogeneous physical conditions of the matrix, may create local communities that vary in their ability to detrimentally invade the carapace.

\section{Causative Factors Involved in the Emergence of ESD}

The emergence, prevalence, and severity of disease state in an animal results from the synergistic interaction of the pathogen, host, and environment. These three components can be represented as intersecting circles, where the intersection is the disease event (Snieszko 1973). The necessary tripartite causal factors of the diseased state are important conceptually, but this initial model does not appear to adequately address ESD in American lobsters. Primary to this is the presumption that the causal bacteria are ubiquitous in the environment and do not appear at this time to be of an unusual strain. Epizootic shell disease is not a case of a sudden appearance of a novel pathogenic bacterial strain that causes an outbreak. Thus, Sindermann (1991) created a conceptual model, later modified by Castro et al. (2006), to advance the idea of serial interactions between the environment, host, and pathogen and the presence of feedback loops. Between Sindermann (1991) and Castro et al. (2006), 10 hypotheses were proposed relating either the state of the host or environment (Table 2) to crustacean shell disease. However, five of the hypotheses rely on external environmental conditions (offshore environ- 
TABLE 2.-Ten hypotheses relating to shell disease in American lobsters and the implicit causal modality described in each hypothesis.

\begin{tabular}{lc}
\hline \multicolumn{1}{c}{ Hypothesis } & Environment \\
\hline (1) Chitin deposition is an important defense mechanism & Host \\
(2) Shell disease is an external indication of metabolic disturbance or trauma & $\mathrm{X}$ \\
compounded by bacterial activity $^{\mathrm{a}}$ & $\mathrm{X}$ \\
(3) Shell disease is associated with failure of external defense and wound repair & $\mathrm{a}$ \\
(4) Shell disease is less important in short-lived species & \\
(5) Shell disease results in population effects & $\mathrm{X}$ \\
(6) Shell disease may be prevalent in offshore deepwater crustaceans & \\
(7) Pollutants (or other stressors) may exacerbate onset or severity of shell disease ${ }^{\mathrm{a}}$ & $\mathrm{X}$ \\
(8) Shell disease is controllable in captive or cultured crustaceans & $\mathrm{X}$ \\
(9) Shell disease prevalence is increasing in the wild & $\mathrm{X}$ \\
(10) Increase of shell disease is correlated with anthropogenic stressors & $\mathrm{X}$ \\
\hline
\end{tabular}

a Sindermann (1991).

${ }^{\mathrm{b}}$ Castro et al. (2006).

ments, pollutants, anthropogenic stressors, captivity) to cause stress responses within individual lobsters. For example, pollutants or anthropogenic stressors decrease the immunocompetency of individual lobsters, thus making them less able to fend off bacteria and more prone to shell disease. Based on this observation, we developed the "host susceptibility hypothesis" to place induced responses of the host as the penultimate factor contributing to the onset of shell disease in American lobsters.

The host susceptibility hypothesis states that although numerous environmental and pathological factors may vary around a lobster, it is eventually the lobster's internal state that permits or prevents development of the diseased state. This model is conceptualized here to state the role of host processes on the onset of ESD in American lobsters. This model is developed to elucidate causal mechanisms within the "host" and "physiological upset" compartments of the Snieszko (1973) and Castro et al. (2006) models. In addition to placing the penultimate focus on the host, this model also reintroduces the role of the pathogen (missing from the Castro et al. 2006 model) to account for environment-bacterial interactions and is more compatible with Sneiszko's (1973) original triad model. While the onset of ESD in American lobsters is a result of multiple factors synergistically affecting the diseased state, the host's susceptibility is the final penultimate factor that controls the onset of the disease and thus is conceptually important to elucidate. After developing the model, we present data describing ESD (and where data are lacking, ISD) in American lobsters to ascertain whether they support or refute model predictions.

\section{Host Susceptibility Hypothesis}

A host lobster is susceptible to bacterial pathogens and exhibits a shell-diseased state when the loss of cuticular material $(L)$ exceeds deposition $(D ; L>D)$. This results in a net loss of the shell, which is manifested as a lesion. If $L$ continues to exceed $D$, then the lesion will grow and increase in severity. Factors to consider in structural integrity of the shell include the processes of cuticular growth, maintenance, wound repair, and internal defense mechanisms (Prince et al. 1995) balanced by bacterial degradation, resorption, and natural wear. Thus, the shell-diseased state at any location in the shell can be modeled as

$$
\int_{e_{n}}^{e_{n}+t} P_{c}-H_{i}+W+H_{r}>\int_{e_{n}}^{e_{n}+t} H_{g}+H_{m}+H_{n},
$$

where $L$ is on the left side of the equation and includes cuticle degradation by the pathogen $\left(P_{c}\right)$, the inhibitory effect of host immune functioning on the activity of the pathogen $\left(H_{i}\right)$, any natural processes that wear away the cuticle (natural erosion or degradation $[W]$ ), and resorption of the cuticle during ecdysis $\left(H_{r}\right)$. The right side of the equation assesses $D$ and includes the processes of growth $\left(H_{g}\right)$, maintenance $\left(H_{m}\right)$, and new growth through an inflammatory response $\left(H_{n}\right)$. However, these competing factors are not instantaneous; rather, they are integrated between the last molt period (ecdysis; $\left.e_{n}\right)$ and the time of observation $\left(e_{n}+t\right)$. This cumulative effect within a molt is observed in the graphical representation of this model (Figure 2). It is assumed that $D$ increases in a concave manner because much of the deposition occurs early in the molt cycle. It is also assumed that $L$ increases in a convex manner because of the logarithmic growth function of pathogenic bacteria as well as the demineralization of the shell late in the molt cycle (i.e., $H_{r}$ ). Furthermore, the most significant period of bacterial growth within the molt cycle is relatively late. Lobsters molt in the fall and overwinter with their new shell. When temperatures begin to increase in the spring and into the summer, the bacteria will begin to increase when 
cuticle growth stops and proecdysis (metabolic preparation for the next molt) begins.

Normal conditions of shell deposition and loss do not result in a shell-diseased state (Figure 2). A diseased state occurs when $L$ exceeds $D\left(t_{a}, t_{b}\right.$, or $t_{c}$ on the horizontal axis of Figure 2). Furthermore, the difference between the integral processes ( $L$ and $D$ ) from the time of shell disease onset to the subsequent molt event $\left(e_{n}+t \rightarrow e_{n+1}\right)$ determines the maximum severity $(s)$ of the shell disease lesion. Altering either the $D$ or $L$ curve (decreased or increased, respectively) will result in a diseased state with moderate $s$. However, if altered $D$ and $L$ curves are simultaneously considered (the prime states in Figure 2), the combination results in the earliest onset of the lesion and the greatest $s$ ( $s_{a}$ in Figure 2). The molt represents a complete loss of shell but does not mean that $L$ is greater than $D$. There is biomass discarded with the old shell, which the lobster will often eat to recycle nutrients. Before loss of the shell in the late premolt period, the next shell has already entered the process of growth (Waddy et al. 1995); thus, if Figure 2 could be extended temporally, there would be overlap in growth-loss curves of successive shells.

The most important factor influencing a lobster's health is stress (Evans 2001) or "physiological upset" (Castro et al. 2006). If the factor causing the stress response is extreme or less severe but chronic, the lobster can experience reduced growth and resistance to disease, and decreased survival is the ultimate impact (Iwama et al. 1997). In this model, physiological disruption indicates that the host is susceptible to bacterial degradation of the cuticle. Increased host susceptibility can result from a decrease in $D$, the ability to create and maintain a functional cuticle and mount a sufficient inflammatory response, or through an increase in $L$ because of increased rates of bacterial consumption, decreased defense immunological processes, or continual natural wear. Finally, there is a time element in this model, where the end state is a function of $L$ and $D$. The longer the time ( $t$ ) for which $L$ is greater than $D$, the more severe the diseased state.

\section{Support for the Host Susceptibility Hypothesis}

While the increased levels of ESD are relatively recent, significant effort has been expended to assess demographics of infected animals. Here, we will discuss these observations as they relate to $t, L$, and $D$ within the host susceptibility hypothesis.

Time.-One of the pronounced characteristics of ESD is that it varies with season, host sex, and host size, which all are probably time-associated factors. Disease severity in lobsters is highest in May and June, before the major molt occurs, and lowest in August,

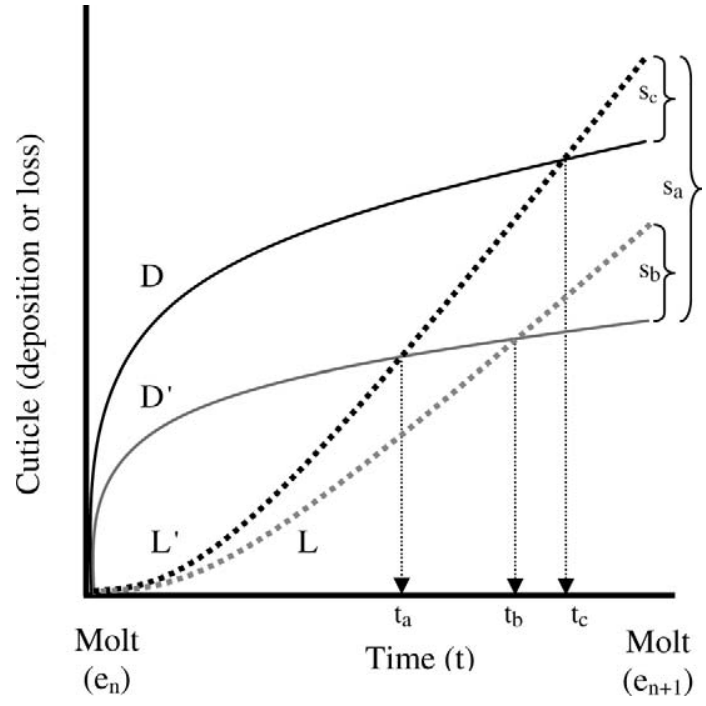

FIGURE 2.-A graphical model of shell disease in an American lobster between two molts (ecdysis; $e_{n}$ and $e_{n+1}$ ). Shell disease occurs when cuticle loss $(L)$ exceeds cuticle deposition, maintenance, and inflammatory responses $(D)$. Under typical conditions, shell disease does not occur. However, if $D$ decreases $\left(D^{\prime}\right)$ or $L$ increases $\left(L^{\prime}\right)$, shell disease will occur. The time $(t)$ of disease onset occurs when $L$ equals $D$ (scenarios $a-c$ ). The disease severity $(s)$ for each scenario is the amount by which $L$ ultimately exceeds $D$.

after most lobsters have molted into new, "clean" shells (Castro et al. 2005; Glenn and Pugh 2005). Glenn and Pugh (2006) observed a positive relationship between water temperature and the prevalence of shell disease. However, the prevalence data are offset and delayed by 1 year. The cumulative effect of the increased temperature increasing $L$ respective to $D$ does not become evident until late in the molt cycle, or 1 year later. While time alone is not sufficient to cause ESD (the diseased state will only occur when host, pathogen, and environment are co-occurring), it is a contributing factor; with increasing time, there is greater opportunity for a diseased state to develop.

In addition, as time between molts $\left(e_{n}\right.$ and $\left.e_{n+1}\right)$ increases, the frequency of observations increases. Epizootic shell disease is observed in all size-classes of lobsters; that is, from larvae (Tlusty 2005) through young of the year (hereafter, age $0 ; \mathrm{R}$. Wahle, University of Southern Maine, personal communication) to adults. However, ESD does not occur with the same frequency across the different size-classes. Few larvae are examined for any shell disease; the disease is ephemeral because of the rapid molt cycle in larvae and is difficult to detect without microscopic assistance. In age-0 sampling, few lobsters were observed with ESD, 
and most were part of the larger size distributions. In Massachusetts, sea sampling indicated that ESD was observed more in larger animals and in females (Glenn and Pugh 2006). Female lobsters molt less frequently than males, primarily because a female's intermolt interval is greater than that of males of equal size (Estrella 1991).

While there may be many factors influencing the sex differences in molt interval and growth, Castro et al. (2006) demonstrated that American lobsters with shell disease exhibited a lower incremental growth per molt than did healthy lobsters because of shorter intermolt intervals. In agreement with the shorter intermolt interval, Laufer et al. (2005) observed that American lobsters with shell disease had significantly higher levels of ecdysones (molting hormones) than healthy lobsters. The purported function of this increase is to cause lobsters with ESD to enter ecdysis sooner than those without ESD. Increasing the rate of molting has the function of decreasing the time in which the lesion grows. While little field evidence supports this association of increased ecdysones in diseased animals (Castro et al. 2006), further assessment is needed to determine whether diseased animals can preferentially molt out of ESD (Rosen 1967; Castro and Angell 2000).

Although increased intermolt periods will favor the onset of shell disease, the onset can occur rapidly, as has been observed in natural populations (Castro et al. 2006).

Cuticle loss and degradation.-While time is necessary for the onset of shell disease, time is not a sufficient condition by itself to cause the disease. Time is a more critical factor when the difference between $L$ and $D$ is small and less of a factor when there is a large disparity between $L$ and $D$. In the above example of Glenn and Pugh's (2006) observation that temperature is correlated to ESD prevalence during the subsequent year, the time factor may be acting on the degradation of the cuticle. Specifically, increased spring and summer temperatures increase bacterial growth and ultimately $P_{c}$. This then derives the later condition, where $L$ exceeds $D$. This relationship is hypothetical, and experiments are necessary to determine the relationship between temperature and $P_{c}$.

The integral process of $L$ may also be influenced by the lobster's ability to mount an immunological defense against bacteria $\left(H_{i}\right)$. There is a correlation between a lobster's initial physiological status and its proclivity to develop ISD, indicating a potential predisposing state (Floreto et al. 2000; Prince and Bayer 2005). Lobsters that developed ISD had significantly lower hemolymph serum protein, glucose, and phosphorus than unaffected lobsters (Floreto et al. 2000). The lower protein content of the hemolymph of affected lobsters implies lower levels of hemocyanin, coagulagen, enzymes, hormones, transport proteins, and free amino acids and therefore suggests an impaired ability to resist infection and to transport nutrients and wastes (Prince and Bayer 2005).

Shell disease may be related to anthropogenic inputs. Within individuals, American lobsters with ISD displayed higher levels of metals (Prince and Bayer 2005), while those with ESD had higher concentrations of alkylphenols (Laufer et al. 2005). Although these studies are correlative and not causative, they suggest that chemical contaminants contribute to the occurrence of the disease, possibly by interfering in immunological functions. De Guise et al. (2005) experimentally linked decreased immunological response to high doses of the pesticide resmethrin.

Natural degradation $(W)$ of the cuticle can instigate shell disease and was considered a prerequisite for development of experimental infections under the assumption that $W$ is necessary before shell disease can breach epicuticular defenses (Malloy 1978). Wear has also been implicated in the onset of shell disease in blue crabs Callinectes sapidus (Noga et al. 1994) and tail fan necrosis in southern rock lobsters Jasus edwardsii (Musgrove et al. 2005).

Shell deposition.-Many marine invertebrates demonstrate the inducible defense of shell thickening in response to predator cues (Trussell and Smith 2000; Freeman and Byers 2006). Lobsters demonstrate a potential for this, as shell thickness varies in relationship to diet (Donahue et al. 1999). Shell thickness is correlated to shell hardness (Donahue et al. 1998), indicating that thicker shells may provide a better defense against predators. It is unknown whether a thicker shell is better able to resist bacterial consumption, although it appears intuitive that the thicker shell will take longer for the lesion to reach the uncalcified endocuticle.

While there is little information on variability in lobster shell thickness and hardness, significantly more information on cuticle formation is available on a mechanistic-process level (Horst and Freeman 1993). The effect of adverse environments may affect cuticle formation and deposition, making the lobster more susceptible to microbial invasion and shell destruction. Sindermann (1979) suggested that ISD results from metabolic disturbance that prevents the lobster from depositing chitin appropriately. Walker et al. (2005) determined that the insecticide methoprene alters the synthesis of chitoproteins in the cuticle and suggested that alteration of chitoprotein synthesis affects the quality of the postmolt shell.

Referring back to the initial discussion of increased temperatures affecting the prevalence of shell disease, a 
potential mechanism to explain the correlation between increased temperature and shell disease is that structural errors occur in the formation of the chitinoprotein matrix at increased temperatures. The resultant structural deficiencies then make the individual more susceptible to bacterial degradation. The microstructure of lobster cuticle is highly organized, and chitinoprotein bundles are deposited in a twisted plywood (Bouligand) structure (Raabe et al. 2005). The endocuticle has a less-compressed Bouligand structure and a lower hardness than the exocuticle (Raabe et al. 2005). With increased growth rates (high temperatures), expanded, less-dense Bouligand structures may lead to overall susceptibility to bacterial consumption. In birds, increased growth rates negatively correlate to strength of the long bones (Leterrier and Nys 1992). This mechanistic answer addressing why shell disease is increased at high temperatures is offered here to suggest that temperature and other environmental factors are affecting lobster health initially at a microstructure scale.

The trade-off between growth and reproduction (Robertson and Butler 2003) may also affect cuticle quality. In particular, the observation that female lobsters exhibit greater prevalence of shell disease than males may reflect a growth-reproduction trade-off. If resources are limited, females may divert more energy to the production of eggs than to the growth, maintenance, and inflammatory response of the existing cuticle (and have an increased time between molts). This "nutritional stress" may be the causal factor for increased prevalence of shell disease in females. While the nutritional stress link has not been directly established for ovigerous females, experimental studies have demonstrated that lobsters on insufficient diets will exhibit a greater prevalence of ISD (Prince et al. 1995). Shell disease may itself be a stressor that reduces the ability of lobsters to grow and deposit cuticle. Stress responses may reduce resources that could be used to mount inflammatory responses $\left(H_{i}\right)$. However, $H_{i}$ in American lobsters with ESD appears to be effective and functioning well in most animals examined (Smolowitz et al. 2005a).

Structural facets of the carapace, such as sensory neurons and pore canals, provide potential avenues for invasion of bacteria (Kunkel et al. 2005). Whether during or after cuticle formation, the potential for inappropriate deposition or distribution of microconstituents of the cuticle warrants further exploration of the fine-resolution methodology of shell deposition (Kunkel et al. 2005). Finally, recent examples indicate that the structural integrity of animals dependent on calcium carbonate is changing in association with climate change (Kleypas et al. 1999). If shell disease is exacerbated by deficiencies in the microconstituents of the cuticle, then minor changes in ocean chemistry should be examined for their role in shell formation, cuticular deficiencies, and ESD. Epizootic shell disease must therefore be addressed in the context of ocean health and global warming.

\section{Does the Lack of Experimental Infections Refute the Host Susceptibility Hypothesis?}

Although research on ISD has occurred since the 1930s (Hess 1937) and it is of obvious economic significance, this disease cannot be easily manipulated in the laboratory. Malloy (1978) is the only researcher to date who experimentally infected presumably healthy American lobsters with ISD. Other attempts to transmit the disease have not been successful (Hess 1937; Prince 1997; Chistoserdov et al. 2005a). There have been incidental cases in which ISD was not intentionally transferred but instead appeared in association with use of a particular diet (Prince et al. 1995) or as an artifact of holding in captivity (Fisher et al. 1978). However, the lack of success in intentionally transferring the disease does not disprove the host susceptibility hypothesis. Rather, it helps to confirm the importance of host susceptibility in the onset of shell disease. Malloy (1978) experimentally induced ISD by holding the lobsters in overcrowded (e.g., stressful) conditions (Getchell 1989), which increased their susceptibility. Overall, host susceptibility may govern more than the response to chitinolytic bacteria. Robohm et al. (2005) observed that American lobsters will survive a single environmental stress, while the same environmental condition in conjunction with one or more additional stressors will decrease their survival. Thus, multiple environmental stressors cause greater susceptibility to homeostasis and regulatory problems, making the lobsters less likely to survive challenges.

The second possibility in observing a variable response to attempted experimental infections is localized population variability in the ability to resist bacterial degradation. Some populations exhibit less shell disease than expected. American lobsters show lower rates of shell disease in western LIS than in the other areas of LIS (McKown et al. 2005). The western LIS population dramatically decreased during a die-off in the late 1990s; thus, this population may have undergone a selection event resulting in increased shell disease resistance in extant lobsters. During research on ISD, Prince and Bayer (2005) observed a greater incidence of shell disease in American lobsters from Nova Scotia than in lobsters from other areas. This suggests that some populations have already experienced selection for disease resistance and that 
experimental infections are easier to create in certain source populations.

The inability to experimentally control a disease's onset and the failure to fulfill Koch's postulates do not automatically devalue the status or importance of the disease. Fibropapillomatosis in green sea turtles Chelonia mydas is a disease of epizootic status and is a result of multiple causative agents (Aguirre and Lutz 2004), although Koch's postulates have not been met (Work et al. 2003). Typhoid fever, leprosy, syphilis, and malaria are all diseases in which Koch's postulates cannot be fulfilled (Evans 1993; Thagard 1999). Thus, the host susceptibility hypothesis is instrumental in identifying processes that serially precede the onset of shell disease and functions as a method to aid the categorization of potential causes and correlates.

\section{Is the Host Susceptibility Hypothesis Complete?}

The host susceptibility hypothesis and supporting model developed here are initial steps in conceptualizing the factors necessary for the onset of ESD in American lobsters. In developing this model, there are basic questions surrounding some of the parameters (particularly $D$ ) that should be further addressed. Furthermore, the model treats the entire cuticle as a uniform structure, whereas it is actually a complex, layered structure (Raabe et al. 2005). Outermost is the epicuticle, a layer composed of lipids deposited by the tegmental glands during the initial stages of the molt cycle. The tegmental glands regress late in the molt cycle, and the natural loss of the lipid layer may make the lobster more susceptible to bacterial invasion at this time. In the context of this model, the maintenance of the epicuticle may decrease to a point where $L$ is greater than $D$, allowing bacteria to gain purchase in the exocuticle. Similarly, the overall contribution of cuticular wear $(W)$ to the onset of shell disease may be significantly more important in the epicuticle than in the endocuticle, while the reverse is true for $H_{i}$. Thus, while each cuticle layer may need to be considered separately for each parameter of the model, a wholesale expansion of each parameter to each cuticular layer is not warranted. Overall, the structure of the model presented here appears to be robust.

The one issue that this model does not directly address is the relationship between subsequent molts. Carryover effects between molts are a part of the overall guise of host susceptibility, and there are a number of ways such effects can be integrated into the current host susceptibility model (Figure 2). The primary point of integration is that $s$ and the carryover between successive molts will be integrated as a greater susceptibility at the beginning of the molt and will be implemented as an altered deposition state within the cuticle. It will be intriguing to see whether there is any relationship between the exact locations of lesions in successive molts.

Finally, it is unknown whether etiology is similar between ISD and ESD. The host susceptibility hypothesis addresses general features of the cuticle that make it susceptible to bacterial degradation. To develop this model, results of studies on all types of cuticular degeneration in lobsters were assessed. However, this model has the potential to differentiate ISD from ESD. A study by Fisher et al. (1978) indicates the importance of high rates of bacterial growth; thus, ISD operates primarily through the left side of the equation $(L)$. The mode of attack is also indicative of increased bacterial loading. The progression of ESD suggests that problems in shell deposition are of more importance. More work is needed to refine this model and to determine the parameters associated with the different forms of shell disease.

\section{Conclusions}

Epizootic shell disease is having a major impact on the health and mortality of some American lobster populations, its effects being transferred to the economics of the fishery. Modeling of fishery independent abundance estimates showed that mortality rate from the settler-to-prerecruit life stage had a density-dependent component and a component associated with shell disease (Gibson and Wahle 2005).

While the onset and progression of ESD in American lobsters is undoubtedly multifactorial, there is little understanding of the direct causality of this disease. The host susceptibility hypothesis is developed here to provide a basis in which this disease can be conceptualized. What is apparent is the difficulty to assess the pathogenesis of a disease and overall "abnormal" conditions when, in many cases, there is not a complete understanding of normal processes. The conceptual shell disease model developed here determined that $L, D$, and $t$ must be integrated to understand disease onset and severity. To understand these three components of shell disease, a key necessity will be to develop a laboratory model in which lobsters can be experimentally infected. This would allow for controlled laboratory experiments that would result in elucidation of the various factors influencing the onset of ESD and allow an examination of potential treatments and remedies. Within this model, the critical components identified in this review that should be thoroughly examined include bacterial degradation of the carapace, carapace formation response, and inflammatory response; the effects of temperature and other environmental factors on these processes; and the role 
of the innate immune system in mitigating bacterial carapace degradation.

Although ESD is not the only disease impacting American lobster health, it is a key disease to understand. The prevalence and severity of the disease can be influenced by the pathogen (type, density, pathogenicity), internal factors (shell quality, nutritional status), and the environment (ocean temperatures, current patterns, microbial communities). The bacteria implicated in cuticular degeneration are ubiquitous in the marine environment (Chistoserdov et al. 2005b). Thus, barring the discovery of a particularly aggressive strain, the increased incidence of shell disease in American lobsters is a result of changes in susceptibility of the host, either directly or indirectly, via environmental changes mediated through a change in host susceptibility. The model developed here provides a framework by which parameters can be systematically addressed for their overall contribution to the onset of shell disease. Only by fully addressing host responses will researchers fully understand how this and other diseases affect American lobster populations and the management methods necessary to control the spread of ESD.

\section{Acknowledgments}

This model was a culmination of the input of numerous lobster biologists who participated in the State of Lobster Science: Lobster Shell Disease Workshop held on March 12-13, 2005, at the University of Massachusetts, Boston (full proceedings available from M.F.T.). We thank all who participated in this meeting and subsequent discussions. This manuscript was greatly improved through the comments of R. Cawthorn and two anonymous reviewers. Significant financial support for the workshop was provided by Darden Restaurants and the Sudbury Foundation, and we are indebted to G. Williams (Darden) and D. Tanner (Sudbury) for their assistance.

\section{References}

Aguirre, A. A., and P. L. Lutz. 2004. Marine turtles as sentinels of ecosystem health: is fibropapillomatosis an indicator? EcoHealth 1:275-283.

Balcom, N., and P. Howell. 2006. Responding to a resource disaster: American lobsters in Long Island Sound 19992004. Connecticut Sea Grant, CTSG-06-02, Groton, Connecticut.

Bullis, R. A. 1988. Shell disease in impounded American lobsters, Homarus americanus. Biological Bulletin 177:327.

Burns, C. D., M. E. Berrigan, and G. E. Henderson. 1979. Fusarium sp. infection in the freshwater prawn Macrobrachium rosenbergii (De Man). Aquaculture 16:193198.
Castro, K. M., and T. E. Angell. 2000. Prevalence and progression of shell disease in American lobster, Homarus americanus, from Rhode Island waters and the offshore canyons. Journal of Shellfish Research 19:691-700.

Castro, K., T. Angell, and B. Somers. 2005. Lobster shell disease in southern New England: monitoring and research. Pages 165-172 in M. F. Tlusty, H. O. Halvorson, R. M. Smolowitz, and U. Sharma, editors. Lobster shell disease workshop. New England Aquarium, Aquatic Forum Series 05-1, Boston.

Castro, K., M. R. J. Factor, T. Angell, and T. Landers. 2006. The conceptual approach to lobster shell disease revisited. Journal of Crustacean Biology 26:646-660.

Chistoserdov, A. Y., S. L. Gubbala, R. M. Smolowitz, F. Mirazol, and A. Hsu. 2005a. A microbiological assessment of epizootic shell disease in the American lobster indicates its strictly dermal etiology. Pages $12-20$ in M. F. Tlusty, H. O. Halvorson, R. M. Smolowitz, and U. Sharma, editors. Lobster shell disease workshop. New England Aquarium, Aquatic Forum Series 05-1, Boston.

Chistoserdov, A. Y., R. M. Smolowitz, F. Mirasol, and A. Hsu. 2005b. Culture-dependent characterization of the microbial community associated with epizootic shell disease lesions in the American lobster, Homarus americanus. Journal of Shellfish Research 24:741-748.

De Guise, S., J. Maratea, E. S. Chang, and C. Perkins. 2005. Resmethrin immunotoxicity and endocrine disrupting effects in the American lobster (Homarus americanus) upon experimental exposure. Journal of Shellfish Research 24:781-786.

Donahue, D. W., R. C. Bayer, and J. G. Riley. 1998. Effects of diet on weight gain and shell hardness of new-shell American lobster, Homarus americanus. Journal of Applied Aquaculture 8(2):79-85.

Donahue, D. W., R. C. Bayer, J. G. Riley, A. A. Bushway, P. B. Brown, R. A. Hazen, K. E. Moore, and D. A. deBruyne. 1999. The effect of soy-based diets on weight gain, shell hardness and flavor of the American lobster (Homarus americanus). Journal of Aquatic Food Product Technology 8:69-77.

Estrella, B. 1991. Shell disease in American lobster (Homarus americanus, H. Milne Edwards, 1937) from Massachusetts coastal waters with considerations for standardizing sampling. Journal of Shellfish Research 10:483-488.

Evans, A. S. 1993. Causation and disease: a chronological journey. Plenum, New York.

Evans, L. H. 2001. Lobster health and disease: basic concepts. Pages 3-8 in L. H. Evans and J. B. Jones, editors. Proceedings of the international symposium on lobster health management. Curtain University of Technology, Bentley, Western Australia.

Fisher, W. S., E. H. Nilson, J. F. Steenbergen, and D. V. Lightner. 1978. Microbial diseases of cultured lobsters: a review. Aquaculture 14:115-140.

Floreto, E. A. T., D. L. Prince, P. B. Brown, and R. C. Bayer. 2000. The biochemical profiles of shell-diseased American lobsters, Homarus americanus Milne Edwards. Aquaculture 188:247-262.

Freeman, A. S., and J. E. Byers. 2006. Divergent induced responses to an invasive predator in marine mussel populations. Science 313:831-833. 
Getchell, R. G. 1989. Bacterial shell disease in crustaceans: a review. Journal of Shellfish Research 8:1-6.

Gibson, M., and R. Wahle. 2005. Reduced recruitment of inshore lobster in Rhode Island in association with an outbreak of shell disease and management implications. Pages 115-130 in M. F. Tlusty, H. O. Halvorson, R. M. Smolowitz, and U. Sharma, editors. Lobster shell disease workshop. New England Aquarium, Aquatic Forum Series 05-1, Boston.

Glenn, R., and T. L. Pugh. 2005. Observations on the chronology and distribution of lobster shell disease in Massachusetts coastal waters. Pages 141-155 in M. F. Tlusty, H. O. Halvorson, R. M. Smolowitz, and U. Sharma, editors. Lobster shell disease workshop. New England Aquarium, Aquatic Forum Series 05-1, Boston.

Glenn, R., and T. Pugh. 2006. Epizootic shell disease in American lobster (Homarus americanus) in Massachusetts coastal waters: interactions of temperature, maturity, and intermolt duration. Journal of Crustacean Biology 26:639-645.

Goarant, C., R. Brizard, and A. L. Marteau. 2000. A white spot disease-like syndrome in the Pacific blue shrimp (Litopenaeus stylirostris) as a form of bacterial shell disease. Aquaculture 185:25-30.

Green, S. L., D. M. Bouley, R. J. Tolwani, K. S. Waggie, B. D. Lifland, G. M. Otto, and J. E. Ferrell. 1999. Identification and management of an outbreak of Flavobacterium meningosepticum infection in a colony of South African clawed frogs (Xenopus laevis). Journal of the American Veterinary Medical Association 214:1833-1838.

Hall-Stoodley, L., J. W. Costerton, and P. Stoodley. 2004. Bacterial biofilms: from the natural environment to infectious diseases. Nature Reviews Microbiology 2:95-108.

Hess, E. A. 1937. Shell disease in lobsters (Homarus americanus) caused by chitiniverous bacteria. Journal of the Biological Board of Canada 3:358-362.

Horst, M. N., and J. A. Freeman, editors. 1993. The crustacean integument: morphology and biochemistry. CRC Press, Ann Arbor, Michigan.

Hsu, A. C., and R. M. Smolowitz. 2003. Scanning electron microscopy investigation of epizootic lobster shell disease in Homarus americanus. Biological Bulletin 205:228-230.

Ivanov, V., O. Stabnikova, P. Sihanonth, and P. Menasveta. 2006. Aggregation of ammonia-oxidizing bacteria in microbial biofilm on oyster shell surface. World Journal of Microbiology and Biotechnology 8:807-812.

Iwama, G. K., A. D. Pickering, J. P. Sumpter, and C. B. Schreck, editors. 1997. Fish stress and health in aquaculture. Cambridge University Press, Cambridge, UK.

Kleypas, J. A., R. W. Buddemeier, D. Archer, J. Gattuso, C. Langdon, and B. N. Opdyke. 1999. Geochemical consequences of increased atmospheric carbon dioxide on coral reefs. Science 284:118-120.

Kluge, J. P. 1965. A granulomatuous disease of fish produced by flavobacteria. Pathologia Veterinaria 2:545-552.

Kunkel, J. G., M. J. Jercinovic, D. Calihan, R. M. Smolowitz, and M. F. Tlusty. 2005. Electron microprobe measurement of mineralization of American lobster, Homarus americanus, cuticle proof of concept. Pages 76-82 in M. F. Tlusty, H. O. Halvorson, R. M. Smolowitz, and U. Sharma, editors. Lobster shell disease workshop. New England Aquarium, Aquatic Forum Series 05-1, Boston.

Landers, D. F. 2005. Prevalence and severity of shell disease in American lobster Homarus americanus from eastern Long Island Sound, Connecticut. Pages 94-97 in M. F. Tlusty, H. O. Halvorson, R. M. Smolowitz, and U. Sharma, editors. Lobster shell disease workshop. New England Aquarium, Aquatic Forum Series 05-1, Boston.

Laufer, H., N. Demir, and W. Biggers. 2005. Response of the American lobster to the stress of shell disease. Journal of Shellfish Research 24:757-760.

Lawrence, J. R., D. R. Korber, B. D. Hoyle, J. W. Costerton, and D. E. Caldwell. 1991. Optical sectioning of microbial biofilms. Journal of Bacteriology 173:6558-6567.

Leterrier, C., and Y. Nys. 1992. Composition, cortical structure and mechanical properties of chicken tibiotarsi: effect of growth rate. British Poultry Science 33:925939.

Malloy, S. C. 1978. Bacteria induced shell disease of lobsters (Homarus americanus). Journal of Wildlife Diseases $14: 2-10$

McKown, K., R. Burgess, and P. Nunnenkamp. 2005. Incidence of shell disease in American lobster (Homarus americanus) in New York waters. Pages 173-176 in M. F. Tlusty, H. O. Halvorson, R. M. Smolowitz, and U. Sharma, editors. Lobster shell disease workshop. New England Aquarium, Aquatic Forum Series 05-1, Boston.

Musgrove, R. J., M. C. Geddes, and T. Conner. 2005. Causes of tail fan necrosis in the southern rock lobster, Jasus edwardsii. New Zealand Journal of Marine and Freshwater Research 39:293-304.

Neville, A. C. 1975. Biology of the arthropod cuticle: zoophysiology and ecology, volumes 4-5. SpringerVerlag, Berlin.

Noga, E. J., D. P. Engel, R. W. Arroll, S. McKenna, and M. Davidian. 1994. Low serum antibacterial activity coincides with increased prevalence of shell disease in blue crabs Callinectes sapidus. Diseases of Aquatic Organisms 19:121-128.

O'Kelly, C. J. 2005. The lobster back biofilm: possible role of the total microbial community in lobster shell diseases. Pages 22-24 in M. F. Tlusty, H. O. Halvorson, R. M. Smolowitz, and U. Sharma, editors. Lobster shell disease workshop. New England Aquarium, Aquatic Forum Series 05-1, Boston.

Okutani, K., and H. Kitada. 1968. Studies on chitin decomposing bacteria present in digestive tracts of aquatic animals III: formation of organic acids. Bulletin of the Japanese Society of Scientific Fisheries 34:11411146.

Porter, L., M. Butler, and R. H. Reeves. 2001. Normal bacterial flora of the spiny lobster Panulirus argus and its possible role in shell disease. Marine and Freshwater Research 52:1401-1405.

Prince, D. L. 1997. Studies on the etiology and pathogenesis of shell disease in the American lobster, Homarus americanus. Doctoral dissertation. University of Maine, Orono.

Prince, D. L., and R. C. Bayer. 2005. Are all lobsters created equal? Understanding the role of host-susceptibility in 
the development of shell disease in Homarus americanus. Pages 58-67 in M. F. Tlusty, H. O. Halvorson, R. M. Smolowitz, and U. Sharma, editors. Lobster shell disease workshop. New England Aquarium, Aquatic Forum Series 05-1, Boston.

Prince, D. L., R. C. Bayer, M. L. Gallagher, and M. Subrainanyam. 1995. Reduction of shell disease with an experimental diet in a Nova Scotian lobster pound. Journal of Shellfish Research 14:205-207.

Raabe, D., C. Sachs, and P. Romano. 2005. The crustacean exoskeleton as an example of a structurally and mechanically graded biological nanocomposite material. Acta Materialia 53:4281-4292.

Robertson, D. N., and M. J. Butler. 2003. Growth and size at maturity in the spotted spiny lobster, Panulirus guttatus. Journal of Crustacean Biology 23:265-272.

Robohm, R. A., A. F. J. Draxler, D. Wieczorek, D. Kapareiko, and S. Pitchford. 2005. Effects of environmental stressors on disease susceptibility in American lobsters: a controlled laboratory study. Journal of Shellfish Research 24:773-780.

Rosen, B. 1967. Shell disease of the blue crab, Callinectes sapidus. Journal of Invertebrate Pathology 9:348-353.

Rosen, B. 1970. Shell disease of aquatic crustaceans. Pages 409-415 in S. F. Snieszko, editor. A symposium on diseases of fishes and shellfishes. American Fisheries Society, Special Publication 5, Bethesda, Maryland.

Sindermann, C. J. 1979. Pollution-associated disease and abnormalities of fish and shellfish: a review. U.S. National Marine Fisheries Service Fishery Bulletin 76:171-749.

Sindermann, C. J. 1991. Shell disease in marine crustaceansa conceptual approach. Journal of Shellfish Research 10:491-494.

Smolowitz, R. M., R. A. Bullis, and D. A. Abt. 1992. Pathologic cuticular changes of winter impoundment shell disease preceding and during intermolt in the American lobster, Homarus americanus. Biological Bulletin 183:99-112.

Smolowitz, R. M., A. Chistoserdov, and A. Hsu. 2005a. A pathological description of epizootic shell disease in the American lobster Homarus americanus. Journal of Shellfish Research 24:749-756.

Smolowitz, R. M., A. Chistoserdov, and A. Hsu. 2005b. Epizootic shell disease in the American lobster, Homarus americanus. Pages 2-11 in M. F. Tlusty, H. O. Halvorson, R. M. Smolowitz, and U. Sharma, editors. Lobster shell disease workshop. New England Aquarium, Aquatic Forum Series 05-1, Boston.

Snieszko, S. F. 1973. The effects of environmental stress on outbreak of infectious diseases of fishes. Journal of Fish Biology 6:197-208.

Stewart, J. E. Disease. Pages 321-329 in J. S. Cobb and B. F. Phillips, editors. The biology and management of lobsters, volume 11. Physiology and behavior. Academic Press, New York.

Stoodley, P., D. deBeer, and Z. Lewandowski. 1994. Liquid flow in biofilm systems. Applied and Environmental Microbiology 60:2711-2716.

Suci, P. A., and B. J. Tyler. 2003. A method for discrimination of subpopulations of Candida albicans biofilm cells that exhibit relative levels of phenotypic resistance to chlorhexidine. Journal of Microbiological Methods 53:313-325.

Sullivan, E. R., and K. M. Nelson. 2005. A comparison of bacterial diversity and abundance on healthy and shelldiseased American lobsters. Pages 45-47 in M. F. Tlusty, H. O. Halvorson, R. M. Smolowitz, and U. Sharma, editors. Lobster shell disease workshop. New England Aquarium, Aquatic Forum Series 05-1, Boston.

Thagard, P. 1999. How scientists explain disease. Princeton University Press, Princeton, New Jersey.

Tlusty, M. F. 2005. New in vivo methods to measure shell formation and possible implications for the study of shell disease. Pages 68-71 in M. F. Tlusty, H. O. Halvorson, R. M. Smolowitz, and U. Sharma, editors. Lobster shell disease workshop. New England Aquarium, Aquatic Forum Series 05-1, Boston.

Trussell, G. C., and D. L. Smith. 2000. Induced defenses in response to an invading crab predator: an explanation of historical and geographic phenotypic change. Proceedings of the National Academy of Sciences of the USA 97:2123-2127.

Vogan, C. L., C. Costa-Ramos, and A. F. Rowley. 2002. Shell disease syndrome in the edible crab, Cancer pagurusisolation, characterization and pathogenicity of chitinolytic bacteria. Microbiology 148:743-754.

Waddy, S. L., D. E. Aiken, and D. P. V. De Klein. 1995. Control of growth and reproduction. Pages 217-266 in J. R. Factor, editor. Biology of the lobster Homarus americanus. Academic Press, San Diego.

Wahle, R. A., L. S. Incze, and M. J. Fogarty. 2004. First projections of American lobster fishery recruitment using a settlement index and variable growth. Bulletin of Marine Science 74:101-114.

Wakabayashi, H., S. Egusa, and J. L. Fryer. 1980. Characteristics of filamentous bacteria isolated from gill diseases of salmonids. Canadian Journal of Fisheries and Aquatic Sciences 37:1499-1504.

Walker, A. N., P. Bush, J. Puritz, T. Wilson, E. S. Chang, T. Miller, K. Holloway, and M. N. Horst. 2005. Bioaccumulation and metabolic effects of the endocrine disruptor methoprene in the lobster, Homarus americanus. Integrative and Comparative Biology 45:118-126.

Work, T. M., G. H. Balazs, M. Wolcott, and R. Morris. 2003. Bacteraemia in free-ranging Hawaiian green turtles Chelonia mydas with fibropapillomatosis. Diseases of Aquatic Organisms 53:41-46. 